\title{
Pengelolaan Dokumentasi Kegiatan Humas pada Institusi di Balai Diklat Lingkungan Hidup dan Kehutanan Kota Pekanbaru
}

\author{
Johan Faladhin', Ulmi Marsya'2, M. Tazri ${ }^{3}$ \\ 1,2,3Universitas Muhammadiyah Riau \\ E-mail: johanfaladhin@umri.ac.id
}

\begin{abstract}
Abstrak
Peningkatan kesadaran akan pentingnya pelestarian lingkungan hidup merupakan hal yang sangat krusial saat ini khususnya di Kota Pekanbaru yang sering terdampak kerusakan lingkungan seperti pembakaran hutan hingga illegal logging. Keberadaan Balai Diklat Lingkungan dan Kehutanan Pekanbaru (BDLHK) Pekanbaru sangat penting disadari oleh masyarakat setra diharapkan mampu memberikan informasi yang valid serta edukatif kepada masyarakat kerkai isu lingkungan. Maka dari itu, dibutuhkan pelatihan pengelolaan company profile lembaga serta pengelolaan informasi yang edukatif, persuasif serta kreatif dengan memanfaatkan platform media sosial yang mampu menjangkau lapisan masyarakat terutama generasi milenial. Luaran kegiatan pengabdian ini ialah pelatihan pengelolaan informasi dan dokumentasi kehumasan yang dalam hal ini berupa, pembuatan company profile institusi, video stop motion, dan social campaign pada media sosial, sehingga kedepannya hubungan kerjasama ini dapat berkelanjutan dengan baik.
\end{abstract}

Kata Kunci: Komunikasi Lingkungan, Company Profile, Media Sosial, Kampanye Sosial.

\begin{abstract}
The importance of environmental awareness must receive a special attention from public especially in Pekanbaru which is often affected by environmental demage such as wildfire or illegal logging. The existence of Balai Diklat Lingkungan dan Kehutanan (BDLHK) of Pekanbaru is expected to be able to provide the valid and educative information about environmental issues. Refers to those issues, they need to improve their abiltity to manage institusion's company profile, informnation management through social media platform, and creating educative, creative, and persuasive content in stop motion video. The purpose of using social media platform is to achieve the society especially youth generation. There are three outputs of this event. first, basic training of making intitusion company profile, second, stop motion video, third, do the social campaign through social media. Hopefully the contribution of this program will be sustainable going forward.
\end{abstract}

Keywords: Environmental Communication, Company Profie, Social Media, Social Campaign.

\section{Pendahuluan}

Instansi Balai Diklat Lingkungan Hidup dan Kehutanan Pekanbaru (BDLHK), pada mulanya merupakan Balai Pendidikan dan Pelatihan Kehutanan Pekanbaru merupakan salah satu Unit Pelaksana Teknis (UPT) pada Departemen Kehutanan yang memiliki 
tugas pokok dan fungsi untuk penyelenggaraan diklat kehutanan. Pelaksanaan tugas pokok dan fungsi tersebut mengacu pada Surat Keputusan Menteri Kehutanan Republik Indonesia Nomor : 094/Kpts-II/1984 tanggal 12 Mei 1984 tentang Organisasi dan Tata Kerja Balai Latihan Kehutanan. Secara umum fungsi dan tugas penyelenggaraan diklat kehutanan tersebut meliputi kegiatan pengkoordinasian, pembinaan dan pelaksanaan diklat di lingkungan Departemen Kehutanan.

BDLHK merupakan salah satu bagian yang sangat strategis dalam pembangunan SDM yang mumpuni untuk pelestarian lingkungan. Penyelenggaraan Diklat Kehutanan ini merupakan upaya untuk meningkatkan kompetensi SDM aparatur kehutanan pada bidang teknis, kepemimpinan, komitmen dan moralitas yang tinggi dalam pembangunan kehutanan khususnya di Riau. Bukan hanya untuk SDM internal saja, penyelenggaraan diklat kehutanan juga dilaksanakan untuk masyarakat dan pihak lain diluar lembaga untuk membentuk kesadaran akan pentingnya pelestarian lingkungan hidup dan juga memberikan pelatihan khusus terkait teknis pelaksanaan berbagai kegiatan yang terkait dengan pembangunan kehutanan.

BDLHK Pekanbaru yang merupakan salah satu Unit Pelaksana Teknis (UPT), yang bertugas untuk penyelenggaraan Diklat Kehutanan termasuk juga kepada masyarakat. Namun, dalam hal pengelolaan informasi yang berkaitan dengan permasalahan lingkungan, seperti penebangan hutan, pembukaan lahan, kabut asap dan lain sebagainya masih belum teroganisir dengan semestinya. Pengelolaan informasi tersebut temasuk juga dalam hal pengelolaan konten media sosial, pembuatan company profile, dan video campaign mengenai isu lingkungan. Hal ini dirasa perlu, agar tidak terjadi tumpang tindih dan seimbang ke masyarakat dengan memanfaatkan berbagai media. (Afhissa \& Parjiyana, 2017).

Maka dari itu, dilakukan proses manajemen kehumasan dengan cara observasi, analisis situasi, perencanaan dan berkelanjutan. Ini tentunya bertujuan untuk mendapatkan pengertian, simpati, dan dukungan dari pihak - pihak terkait baik eksternal maupun internal sehingga dapat membentuk opini publik (masyarakat). Menurut Coulsin \& Thomas (2002), kegiatan humas merupakan suatu bentuk usaha yang direncanakan secara terus menerus untuk membangun dan mempertahankan hubungan baik secara timbal balik antara organisasi dan masyarakatnya. Kegiatan kehumasan ini tentunya menyangkut pengembangan citra dan reputasi oleh sebuah organisasi atau institusi berdasarkan fungsi sosialnya. BDLHK juga membutuhkan peran Humas bukan hanya bertujuan untuk mewujudkan pengembangan reputasi, citra, namun juga untuk memberikan nilai edukasi terkait isu lingkungan kepada masyarakat.

Melalui program kerja "Pengelolaan Dokumentasi Kegiatan Humas pada Institusi" ini diharapkan dapat membantu institusi dalam mengelola informasi dan komunikasi yang baik, agar masyarakat dapat lebih memahami, fungsi dan peranan BDLHK dalam membantu penyelesaian permasalahan yang berkaitan dengan lingkungan dan kehutanan, termasuk juga meningkatkan awareness masyarakat terkait permasalahan lingkungan. 
Adapun beberapa pelatihan yang dirasa penting untuk dilakukan dalam menunjang fungsi dan peran BDLHK dalam mengedukasi masyarakat mengenai tujuan lembaga serta isu-isu lingkungan yaitu dengan memberikan pelatihan teknik pembuatan profil institusi atau company profile, penyebaran informasi melalui media sosial Instagram, serta video stop motion dalam durasi 3 menit.

Melalui kegiatan pengelolaan ini diharapkan seluruh bagian divisi mampu melanjutkan kegiatan pengelolaan dokumentasi kehumasan yang ada pada institusi BDLHK Kota Pekanbaru secara berkelanjutan dikemudian hari. Selain itu, Program Studi Hubungan Masyarakat Univeritas Muhammadiyah Riau juga dapat berkontribusi dalam menerapkan keilmuan dibidang public relations pada lembaga-lembaga sosial masyarakat untuk memenuhi salah satu tugas Tri Dharma perguruan tinggi yaitu pengabdian kepada masyarakat.

\section{Metode}

Mekanisme dan pelaksanaan kegiatan yang dilakukan yakni dengan memberikan pehaman dan membangun kesepakatan dengan mendiskusikan maksud dan tujuan dibuatnya pelatihan pengelolaan informasi serta media bagi institusi. Berdasarkan data yang didapat, bahwa BDLHK Pekanbaru, belum memiliki pengelolaan dokumentasi kegiatan kehumasan yang mumpuni. Baik dalam bentuk produksi konten dan pengelolaan konten media sosial, termasuk juga company profile. Salah satu unsur penting dalam membangun reputasi dan membentuk citra dari sebuah institusi, ialah company profile. Namun, dikarenakan keterbatasan dalam penguasaan cara pengambilan gambar yang baik, pengolahan gambar, editing, pengelolaan serta pembuatan caption dari media sosial, sehingga aspek-aspek tersebut belum terorganisir dengan semestinya.

Seperti bagaimana mengimplementasikan unsur yang menarik dari gambar yang akan di posting hingga pemilihan situasi atau waktu-waktu tertentu yang baik dalam mengelola konten melalui akun sosial media. Maka dari itu, tim dosen dan beberapa mahasiswa dari Program Studi Hubungan Masyarakat yang terlibat dalam kegiatan pengabdian ini, terlebih dahulu melakukan survey, analisis situasi dengan melakukan temu ramah kepada BDLHK Pekanbaru untuk berkolaborasi melalui kerjasama dalam pengelolaan dokumentasi kehumasan tersebut.

Konsep ini tentunya mengacu pada, teori dari Regina Luttrell dalam buku Media Social How to Engage, Share, and Connect menyebutkan The Circular Model of Some bahwa terdapat beberapa tahap yang perlu diperhatikan dalam mengelola media sosial. Terdapat empat aspek dalam model ini, keempat aspek tersebut memiliki kekuatan dalam bagiannya masing-masing, tetapi bersama-sama aspek ini memungkinkan strategi yang solid. Ketika sebuah perusahaan/instansi berbagi (sharing) sesuatu mereka juga dapat mengelola (manage) atau terlibat (engage) dan bahkan mengoptimalkan (optimize) pesan mereka secara bersamaan (Luttrell, 2015). 
Selain itu, hal yang paling penting dalam persiapan untuk mengelola media sosial ialah perlu memperhatikan unsur tujuan, sasaran, konten, channel, dan ukuran untuk memantau efektivitas kegiatan yang ada pada media sosial sebuah institusi. Seperti yang tertera pada gambar bagan alur berikut ini :

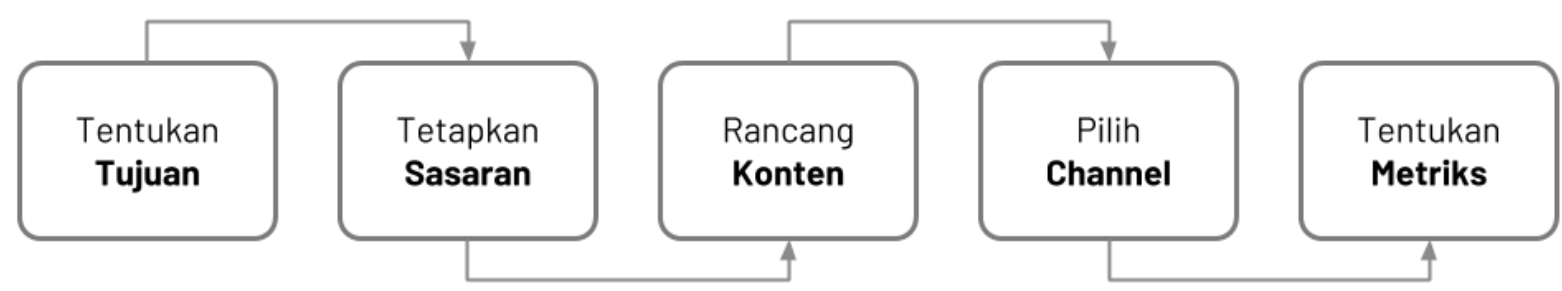

Gambar 1. Tahapan Persiapan Pengelolaan Media Sosial

Mekanisme dalam hal perancangan konsep dari company profile juga ditentukan melalui beberapa unsur menurut (Rifai, Astriyani, \& Indria, 2018) diantaranya :

a. Pra Produksi adalah tahapan perencanaan proses suatu produksi merupakan tahapan awal dari seluruh kegiatan yang akan datang.

b. Storyboard adalah suatu sketsa gambar tersusun berurutan sesuai dengan naskah, dengan storyboard yang telah kita buat untuk menyampaikan ide cerita kita kepada orang lain dengan lebih mudah, karena kita dapat menggiring khayalan seseorang mengikuti gambar yang tersaji, sehingga menghasilkan persepsi yang sama pada ide cerita.

c. Produksi adalah suatu upaya dalam merubah bentuk sinopsis menjadi audio visual seperti diketahui bahwa pelaksanaan produksi dalam program acara tuntutan sinopsis hal tersebut dikarenakan sinopsis merupakan hasil dari penemuan ide untuk suatu program acara.

d. Pasca Produksi tahap produksi selesai maka akan dilakukan tahap pasca produksi yang meliputi offline editing yaitu serangkaian alur konsep tersebut menjadi sesuatu yang tersusun rapi namun masih kasar atau belum menggunakan efekefek tertentu, baru kemudian dilanjutkan ke online editing dengan pemberian effect gambar agar lebih bernuansa bagus dan enak dipandang, diberikan dubbing bila diperlukan, kemudian dilakukan mixing atau suara effect yang disesuaikan dengan program yang sedang diproduksi seperti suara musik serta pemberian tulisan-tulisan (titling) bila program tersebut memerlukan informasi berupa tulisan atau terjemahan.

Teknis pelaksanaan kegiatan pengabdian ini dilakukan oleh tim dosen dan beberapa mahasiswa dari Program Studi Hubungan Masyarakat dengan menyampaikan beberapa program yang telah dirancang, untuk keberlanjutan pengembangan pengelolaan dokumentasi kehumasan. Melalui program ini, diharapkan dapat memberikan pemahaman dan pengembangan skill bagi karyawan BDLHK Pekanbaru dalam memproduksi dan mengelola konten yang bertujuan sebagai kegiatan 
dokumentasi kehumasan institusi. Pelaksanaan kerjasama dengan Balai Diklat Lingkungan Hidup dan Kehutanan (BDLHK) Pekanbaru ini dilaksanakan dalam kurun waktu kurang lebih satu bulan yakni dari bulan April sampai Juni 2019. Pelaksanaan kerjasama dapat dilihat pada tabel berikut :

Tabel 1. Mekanisme Pelaksanaan Kegiatan

\begin{tabular}{|c|c|c|c|c|}
\hline No & Mekanisme Kegiatan & $\begin{array}{c}\text { Metode } \\
\text { Pelaksanaan } \\
\end{array}$ & Lokasi & Waktu \\
\hline 1 & $\begin{array}{l}\text { Pertemuan pertama yaitu } \\
\text { survey lokasi dan survey } \\
\text { ketersediaan dengan } \\
\text { melakukan analisis situasi pada } \\
\text { BDLHK Pekanbaru untuk } \\
\text { menerima penawaran } \\
\text { kerjasama. }\end{array}$ & Diskusi & $\begin{array}{l}\text { BDLHK } \\
\text { Pekanbaru }\end{array}$ & April 2019 \\
\hline 2 & $\begin{array}{l}\text { Melakukan audiensi dengan } \\
\text { Bapak Kepala Balai Diklat } \\
\text { Lingkungan Hidup dan } \\
\text { Kehutanan (BDLHK) Pekanbaru }\end{array}$ & Diskusi & $\begin{array}{l}\text { BDLHK } \\
\text { Pekanbaru }\end{array}$ & April 2019 \\
\hline 3 & $\begin{array}{l}\text { Pertemuan dengan Bapak Muji } \\
\text { bagian Teknik Komputer dan } \\
\text { Jaringan, berdiskusi mengenai } \\
\text { teknis produksi dan } \\
\text { pengelolaan konten }\end{array}$ & Diskusi & $\begin{array}{l}\text { BDLHK } \\
\text { Pekanbaru }\end{array}$ & April 2019 \\
\hline 4 & $\begin{array}{l}\text { Pengambilan gambar dan video } \\
\text { untuk company profile pada saat } \\
\text { karyawan Balai Diklat } \\
\text { Lingkungan dan Kehutanan } \\
\text { Pekanbaru, rapat bersama } \\
\text { bapak Kepala BDLHK }\end{array}$ & $\begin{array}{l}\text { Ramah Tamah, } \\
\text { Diskusi }\end{array}$ & $\begin{array}{l}\text { BDLHK } \\
\text { Pekanbaru }\end{array}$ & April 2019 \\
\hline 5 & $\begin{array}{l}\text { Pengambilan gambar dan video } \\
\text { ke seluruh ruangan yang telah } \\
\text { disusun di story board company } \\
\text { profile }\end{array}$ & Ramah Tamah & $\begin{array}{l}\text { BDLHK } \\
\text { Pekanbaru }\end{array}$ & April 2019 \\
\hline 6 & $\begin{array}{l}\text { Pengambilan gambar dan video } \\
\text { disaat karyawan Balai Diklat } \\
\text { Lingkungan Hidup dan } \\
\text { Kehutanan (BDLHK) Pekanbaru } \\
\text { melaksanakan kegiatan rutin } \\
\text { setiap minggunya yaitu senam } \\
\text { sehat }\end{array}$ & $\begin{array}{l}\text { Pengambilan } \\
\text { Gambar dan } \\
\text { Video }\end{array}$ & $\begin{array}{l}\text { BDLHK } \\
\text { Pekanbaru }\end{array}$ & April 2019 \\
\hline 7 & $\begin{array}{l}\text { Pengambilan gambar dan video } \\
\text { di ruang makan pada acara } \\
\text { penyambutan kegiatan bulan } \\
\text { Ramadhan }\end{array}$ & $\begin{array}{l}\text { Pengambilan } \\
\text { Gambar dan } \\
\text { Video }\end{array}$ & $\begin{array}{l}\text { BDLHK } \\
\text { Pekanbaru }\end{array}$ & Mei 2019 \\
\hline 8 & $\begin{array}{l}\text { Pertemuan dengan Bapak } \\
\text { Kepala BDLHK membahas } \\
\text { mengenai media sosial Balai } \\
\text { Diklat Lingkungan Hidup dan } \\
\end{array}$ & Diskusi & $\begin{array}{l}\text { BDLHK } \\
\text { Pekanbaru }\end{array}$ & Mei 2019 \\
\hline
\end{tabular}




\begin{tabular}{|c|c|c|c|c|}
\hline & Kehutanan Pekanbaru & & & \\
\hline 9 & $\begin{array}{l}\text { Proses produksi dokumentasi } \\
\text { humas pada institusi Balai } \\
\text { Diklat Lingkungan Hidup dan } \\
\text { Kehutanan Pekanbaru }\end{array}$ & $\begin{array}{l}\text { Pengolahan } \\
\text { Data dan } \\
\text { Editing }\end{array}$ & $\begin{array}{l}\text { Kampus } \\
\text { UMRI - Prodi } \\
\text { Humas }\end{array}$ & Mei 2019 \\
\hline 10 & $\begin{array}{l}\text { Penyerahan hasil produksi } \\
\text { dokumentasi humas pada } \\
\text { institusi Balai Diklat } \\
\text { Lingkungan Hidup dan } \\
\text { Kehutanan Pekanbaru }\end{array}$ & $\begin{array}{l}\text { Diskusi Dan } \\
\text { Pertemuan }\end{array}$ & $\begin{array}{l}\text { BDLHK } \\
\text { Pekanbaru }\end{array}$ & Juni 2019 \\
\hline 11 & $\begin{array}{l}\text { Pembuatan laporan Pengabdian } \\
\text { Kepada Masyarakat }\end{array}$ & $\begin{array}{l}\text { Diskusi, } \\
\text { Pengumpulan \& } \\
\text { Pengolahan } \\
\text { Data }\end{array}$ & $\begin{array}{l}\text { Kampus } \\
\text { UMRI - Prodi } \\
\text { Humas }\end{array}$ & Juni 2019 \\
\hline
\end{tabular}

Rencana keberlanjutan program yang dilakukan melalui kegiatan pengabdian bersama Balai Diklat Lingkungan Hidup dan Kehutanan (BDLHK) Pekanbaru ini, ialah dapat bersinergi melakukan kerjasama di kemudian hari, dengan mengembangkan konten yang berkaitan dengan pengelolaan dokumentasi kehumasan.

Para karyawan atau staf dari Balai Diklat Lingkungan Hidup dan Kehutanan (BDLHK) mampu dan konsisten dalam pengelolaan kegiatan melalui dokumentasi kehumasan yang dilakukan secara berkala. Tentunya memiliki unsur edukatif dan kreatif, sehingga informasi yang disampaikan ke masyarakat dapat dipahami dengan baik dan konten juga bernilai edukatif serta memiliki unsur persuasif untuk mengajak masyarkat lebih peduli linngkungan dan pelestarian lingkungan hidup.

\section{Hasil dan Pembahasan}

Kegiatan pengabdian kepada masyarakat dalam hal ini dilakukan dengan memberikan sumbangsih ide yang diterapkan pada mitra, BDLHK Pekanbaru. Pengelolaan dokumentasi kehumasan di BDLHK Pekanbaru yang dilaksanakan pada tanggal 26 April - 24 Juni 2019 ini, merupakan salah satu bentuk perhatian Program Studi Hubungan Masyarakat Fakultas Ilmu Komunikasi Universitas Muhammadiyah Riau, untuk membagi keilmuan kepada instansi kehumasan yang ada pada institusi pemerintah. Kegiatan pengabdian ini ditujukan kepada seluruh staff umumnya dan bidang kehumasan pada khususnya. Dengan tujuan agar semua bagian dalam institusi mampu dan turut berkontibusi dalam memproduksi serta mengelola konten media sosial yang informatif, persuasif, dan kreatif. Sehingga BDLHK diharapkan membangun hubungan yang baik dengan masyarakat.

Kegiatan ini dilakukan oleh mahasiswa Program Studi Hubungan Masyarakat Fakultas Ilmu Komunikasi Universitas Muhammadiyah Riau dengan berjumlah lima orang yaitu Nadya Sukma Anggraini (170502013), Dara Anjas Aprilia (170502006), Santika (170502007), Syukra Azhary (170502019), Boy Syahril (170502020) dengan dosen pembimbing Johan Faladhin, M.I.Kom (1004098803), Ulmi Marsya, M.A 
(1021038905), M. Tazri, M.A (1002019002). Melalui penerapan program kegiatan dokumentasi kehumasan pada institusi yang diberikan, yakni dengan melakukan pembuatan company profile, pengelolaan media sosial sebagai sarana yang menyebarluaskan informasi kepada publik secara efektif dan efesien. Selain itu, tim dosen dan mahasiswa juga membantu BDLHK dalam melakukan campaign dengan membuat video stop motion mengenai konten edukasi "Cintai Lingkungan" dengan tidak melakukan penebangan hutan.

Kegiatan awal dimulai dengan melakukan audiensi kepada pihak-pihak yang terkait untuk mendapatkan berbagai macam data dalam penyusunan konten untuk company profile dan pengelolaan media sosial. Tentunya dengan melakukan observasi dan analisis situasi kepada Bidang Humas dari BDLHK Pekanbaru.

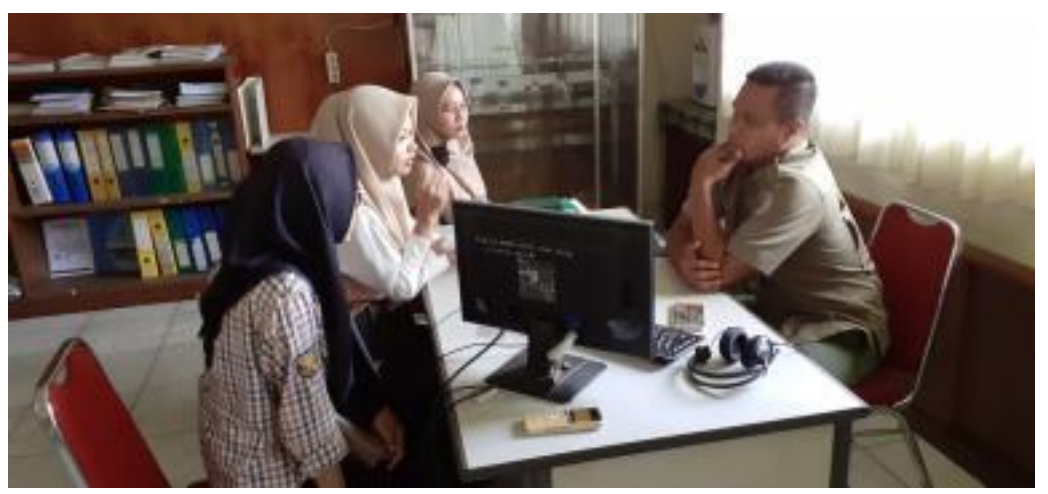

Gambar 2. Audiensi pertama dengan BDLHK Pekanbaru

Melalui audiensi ini kami tim dari dosen dan mahasiswa yang melaksanakan pengabdian, ingin menyampaikan maksud dan tujuan dalam pengabdian ini dengan pihak Balai Diklat Lingkungan Hidup dan Kehutanan (BDLHK) Pekanbaru serta apa saja yang dapat kami bantu dalam hal kehumasan di instansi pemerintahan tersebut untuk citra dan atau pandangan masyarakat terhadap instansi ini.

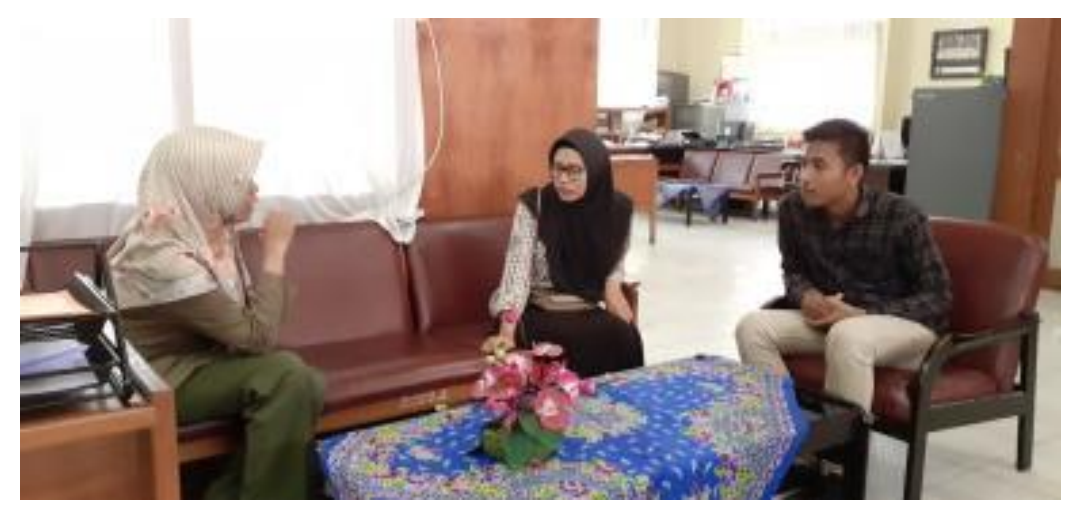

Gambar 3. Audiensi kedua dengan BDLHK Pekanbaru 
Pada pertemuan audiensi kedua ini, tim berdiskusi membahas mengenai penyesuaian jadwal shooting dengan pihak BDLHK Pekanbaru untuk pengambilan gambar pembuatan company profile dari berbagai sudut dan ruangan, agar waktu tidak berbenturan dengan kegiatan lain. Hal ini bertujuan untuk kelancaran proses produksi company profile untuk mendapatkan hasil yang maksimal.
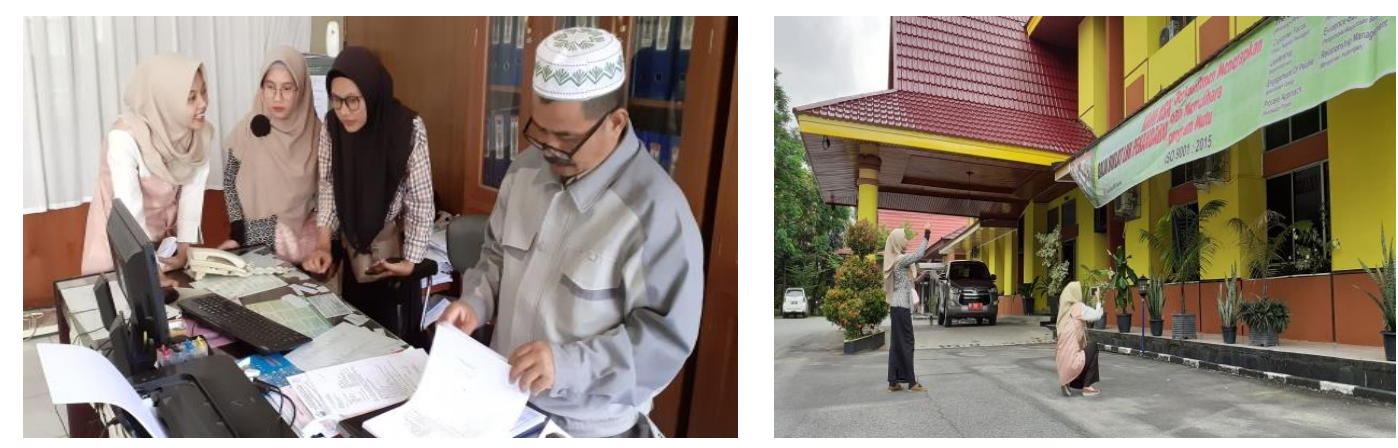

Gambar 4. Produksi Company Profile BDLHK Pekanbaru

Setelah melakukan diskusi serta menyesuaikan jadwal, maka rancangan konsep, setting atau tempat telah disusun untuk melaksanakan proses produksi dengan list shooting berdasarkan timeline atau time schedule yang sudah disesuaikan sebagai berikut: Pada hari Senin, tanggal 29 April 2019 mahasiswa Program Studi Hubungan Masyarakat memulai produksi company profile dengan melakukan pengambilan gambar pada ruang depan dan ruang kerja, yang meliputi Seksi Penyelenggara dan Kerjasama Diklat BDLHK, Seksi Sarana dan Evaluasi Diklat BDLHK, Sub Bagian Tata Usaha BDLHK, Ruang Widya Iswara BDLHK, kemudian dilanjutkan keesokan harinya.

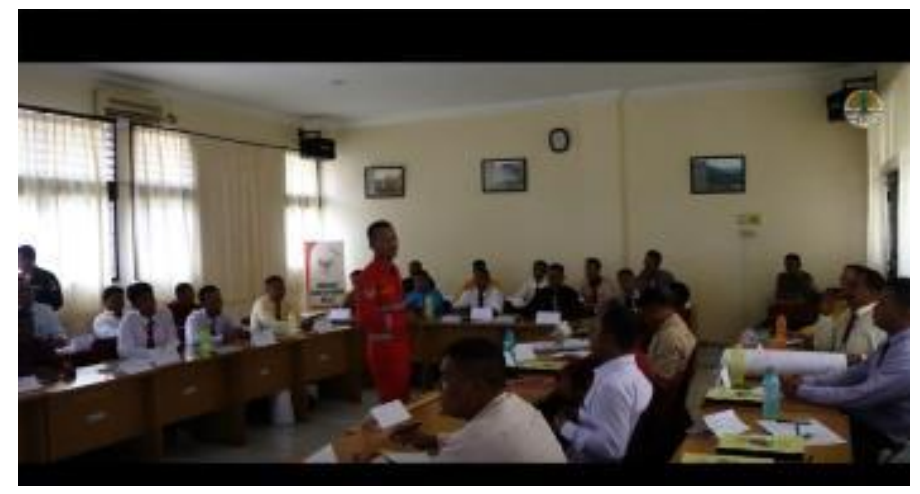

Gambar 5. Shot Visual Company Profile BDLHK pada kegiatan rapat

Pada Selasa, tanggal 30 April 2019 kegiatan dilanjutkan dengan melakukan proses produksi company profile dengan melakukan pengambilan gambar kegiatan Apel Pagi, kemudian dilanjutkan pada perpustakaan, rumah kaca, ruang makan, dan ruang kelas. 


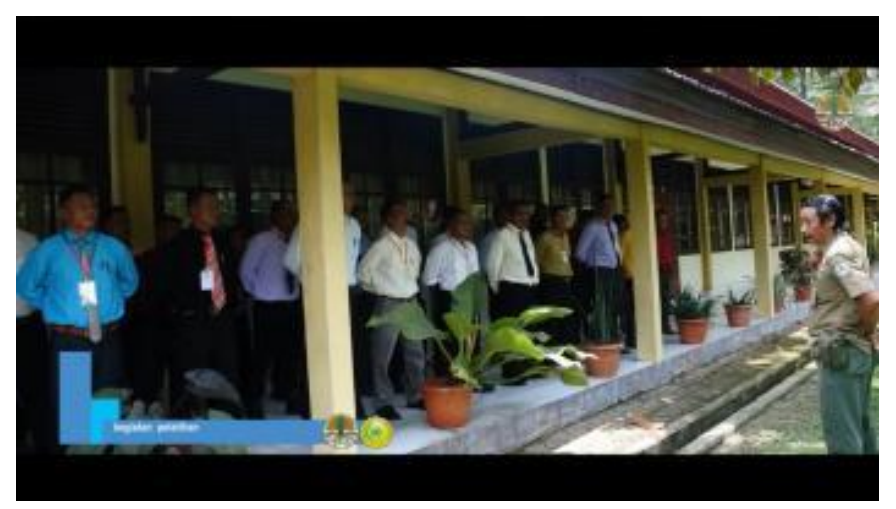

Gambar 6. Shot Visual Company Profile BDLHK pada kegiatan apel pagi

Kemudian, kegiatan dilanjutkan pada hari Rabu, tanggal 1 Mei 2019, dengan mengambil gambar gedung utama menggunakan drone dan mengambil gambar hutan belakang, asrama dan masjid serta mess Mersawa.
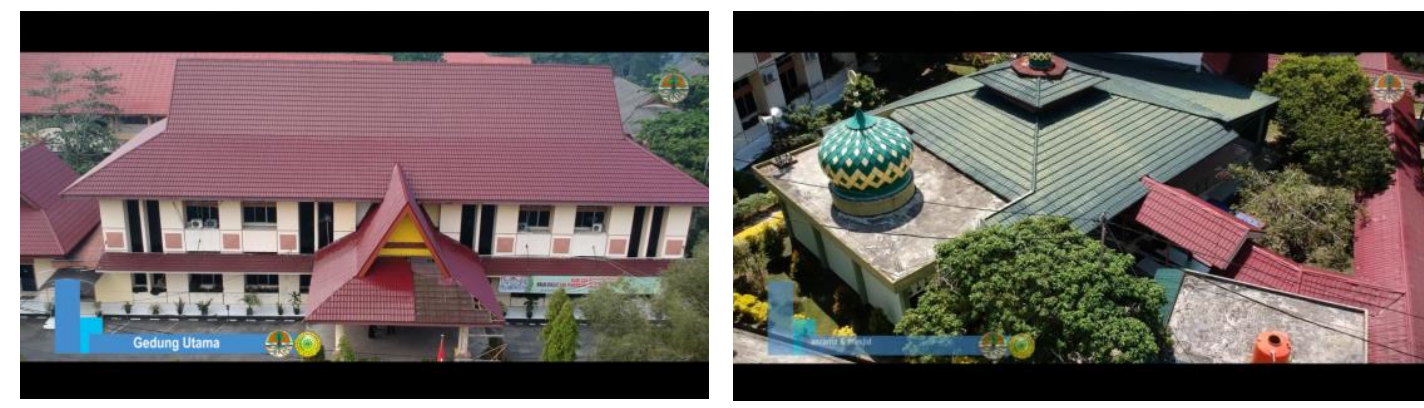

Gambar 7. Shot Visual Company Profile BDLHK, Gedung Utama dan Masjid

Selanjutnya proses pengambilan gambar dilanjutkan pada hari, Kamis, 2 Mei 2019 dengan mengambil gambar pada aktivitas pada saat karyawan melakukan kegiatan senam pagi, kemudian stock shot ruang kesehatan dan ruang laktasi, setelah itu, dilanjutkan pada hari Senin, 6 Mei 2019 dengan pengambilan gambar pada saat melakukan kegiatan rapat dan pelatihan, di hari Selasa, 7 Mei 2019 juga melakukan pengambilan gambar kegiatan pelatihan, dilanjutkan dengan mereview stock shot video lingkungan hutan Suligi, danau Suligi, aren Suligi, dan hutan bambu Bukit Suligi yang berada di Ujung Batu Rokan Hulu berdasarkan arsip yang diberikan oleh pihak BDLHK.

Selain itu, tim pengabdian ini juga membantu dalam hal pengelolaan konten media sosial instagram. Salah satu konten yang dikelola dalam media sosial instagram tersebut, yakni dengan membantu melalui postingan tentang "Penanaman Pohon dalam Rangka Hari Bakti Rimbawan. 


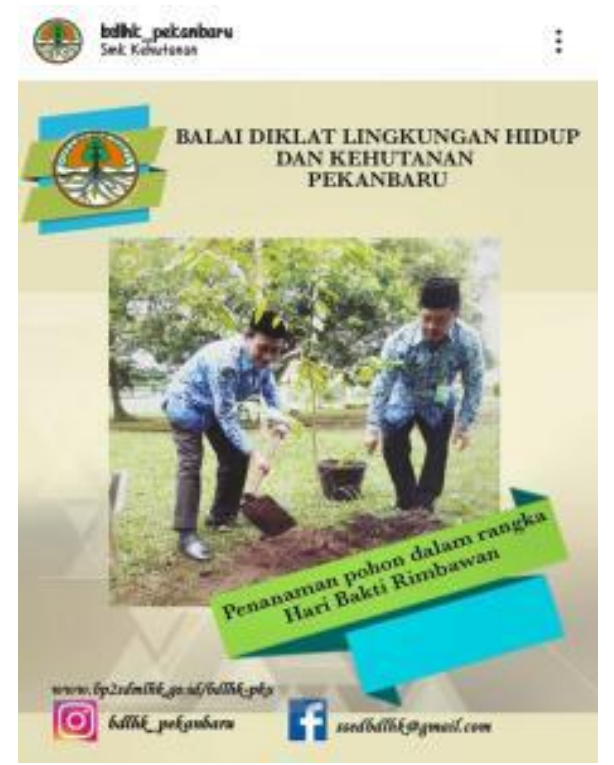

Gambar 8. Screenshot Pengelolaan Konten Media Sosial Instagram BDLHK mengenai

"Penanaman Pohon dalam Rangka Hari Bakti Rimbawan"

Selanjutnya, dalam hal pengelolaan dokumentasi kehumasan yang dilakukan oleh tim pengabdian, ialah dengan membuat social campaign mengenai "Cintai Lingkungan, Penebangan Liar, dan Dampak yang Menyebabkan Banjir" melalui video stop motion yang kemudian video ini akan menjadi materi yang diunggah sebagai konten media sosial instagram BDLHK Pekanbaru.
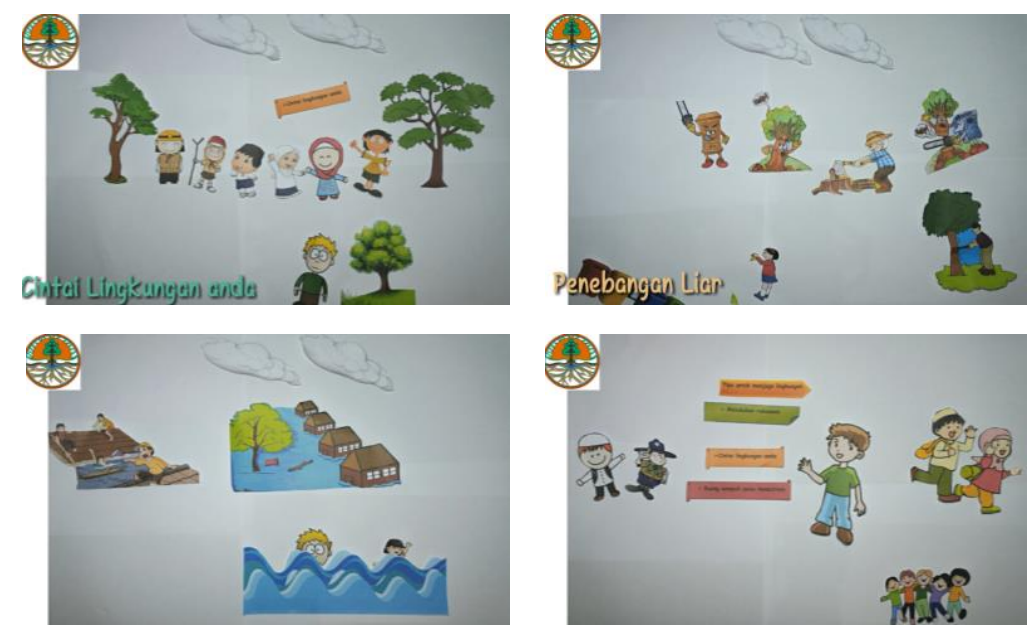

Gambar 9. Screenshot atau Potongan Stop Motion Mengenai Campaign Lingkungan

Kemudian, setelah seluruh file terkumpul tim pengabdian yang membantu produksi company profile dan konten media sosial memulai proses editing seluruh konten selama kurang lebih satu sampai dua minggu. Setelahnya, melalui komunikasi panjang dan melakukan appointment pada hari Senin 17 Juni 2019, tim pengabdian menyerahkan hasil produksi konten yang berupa company profie dan video campaign 


\section{stop motion.}

Setelah melakuan review dari dokumen-dokumen yang digunakan bersama koordinator dari pihak BDLHK Pekanbaru, menyampaikan bahwa terdapat beberapa bagian yang perlu dilakukan perbaikan.. Tim pengabdian melakukan perbaikan seperti yang diminta oleh pihak BDLHK, setelah itu diserahkan kembali kepada pihak BDLHK Pekanbaru. Tahap akhir, tim mendatangi dan mengurus surat keterangan dari BDLHK Pekanbaru, bahwa menerangkan kami sudah melaksanakan pengabdian dan berakhir pada Senin 24 Juni 2019.

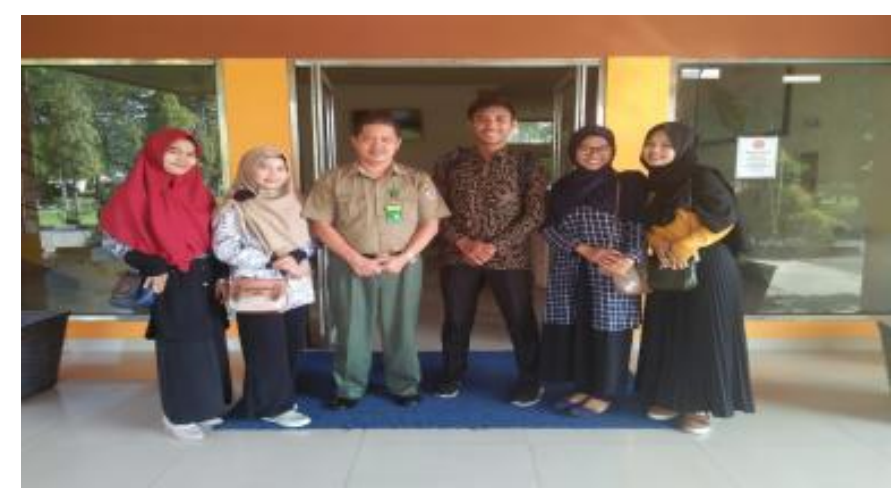

Gambar 10. Foto Bersama dengan Kepala Bagian Umum BDLHK Pekanbaru

\section{Simpulan}

Setelah berjalannya kerjasama ini baik dalam membuat dan menjalankan program yang sudah diuraikan pada bab sebelumnya, pihak Balai Diklat Lingkungan Hidup dan Kehutanan Kota Pekanbaru dapat menerima dan menyambut positif dengan kehadiran kami, baik dosen dan mahasiswa dari Program Studi Hubungan Masyarakat Universitas Muhammadiyah Riau. Melalui program yang kami tawarkan dalam bentuk pengelolaan kegiatan dokumentasi kehumasan pada institusi, diharapkan kedepannya mereka dapat memberikan informasi yang menarik, efektif dan efesien untuk membangun hubungan yang antara pihak lembaga dengan masyarakat maupun antar institusi atau lembaga.

Serta, pengelolaan dokumentasi kehumasan yang telah didapatkan dari kegiatan ini sekaligus dapat bermanfaat dalam pemberian informasi melalui media sosial yang sudah terkelola dengan baik dan dapat menjadi sesuatu hal yang berkelanjutan. Secara keseluruhan, tim pengabdian berharap bahwa kontribusi dalam hal pengerjaan dokumentasi kehumasan pada institusi ini dapat membantu serta bermanfaat bagi BDLHK Pekanbaru dan masyarakat yang membutuhkan informasi tentang pendidikan dan pelatihan lingkungan hidup.

\section{Referensi}

Afhissa, C., \& Parjiyana, P. (2017). Analisis Pelaksanaan Fungsi Pengawasan Pimpinan di Balai Diklat Lingkungan Hidup dan Kehutanan (BDLHK) Pekanbaru. PUBLIKA: 
Jurnal Ilmu Administrasi Publik, 3(2), 207-223.

Ardianto, E. (2011). Handbook of Public Relations. Bandung: Simbiosa Rekatama Media. Assumpta, S.M. (2005). Dasar Dasar Public Relations. Jakarta: Grasindo.

BDLHK Pekanbaru,. http://elearning.menlhk.go.id/mod/page/view.php?id=26867

Coulson., \& Thomas, C. (2002). Public Relations Pedoman Praktis Untuk PR, Jakarta: PT. Bumi Aksara.

Enterprise, J.. (2015). Cara Membuat Company Profile, Jakarta: Elex Media Komputindo. Indroanto. (2006), Ekologi Hutan, Jakarta : PT. Bumi Aksara.

Luttrell, R. (2015). Social Media : How to Engage, Share, and Connect. United Kingdom: Rowman \& Littlefield.

Mahmudah, S. M., \& Rahayu, M. (2020). Pengelolaan Konten Media Sosial Korporat pada Instagram Sebuah Pusat Perbelanjaan. Jurnal Komunikasi Nusantara, 2(1), 1-9.

Purwono. (2009), Materi Pokok Dasar - Dasar Dokumentasi, Jakarta.

Rifai, D., Astriyani, E., \& Indria, U. (2018). Pembuatan Video Company Profile Sebagai Penunjang Informasi dan Promosi Pada PT. Daiichi Elevator Indonesia. Technomedia Journal, 3(1), 98-109.

Roslan, R. (2012), Manajemen PR dan Media Komunikasi, Bandung: PT. Rajawali Pers.

SK.851/MENLHK/SETJEN/PLA.0/11/2016, (2016). Tentang Penetapan Lokasi Fasilitasi Pada 14 Unit Kesatuan Pengelolaan Hutan Produksi (Kphp) Di Provinsi Riau. http://kph.menlhk.go.id/sinpasdok/public/sk_menhut/UNIT\%20I\%20RIAU/851 \%20RIAU.

Wollenberg, E., Sileuw, A.E., Suporahardjo. (2005). Pembelajaran Sosial dalam Pengelolaan Hutan Komunitas. Bogor: Center for International Forestry Research (CIFOR). 